\section{Urgent appeal for volunteers}

Dental professionals are urgently needed to provide essential treatment for thousands of refugees on the Greek islands of Lesvos and Samos, some of whom cannot eat solid food because their dental pain is so severe.

Dental charity Dentaid is launching new volunteering trips throughout March, April and May 2017 to both islands after seeing the desperate need for dental treatment in the camps. Volunteers will spend a week working as part of a small team. Dentaid has been offered containers to use as a dental surgery. The charity is sending medical supplies, portable and disposable equipment and has made arrangements for sterilisation.

The first trips will be more suitable for dentists and dental nurses as many refugees will need extractions and pain-relieving treatment. Hygienists and therapists will be able to join the teams in

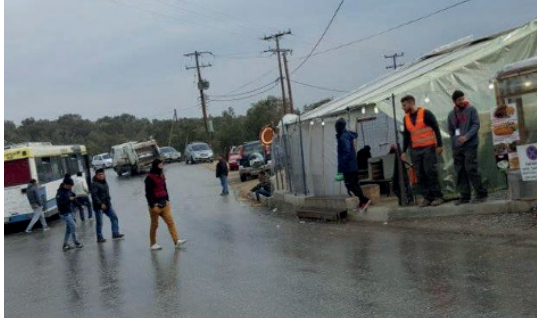

May when Dentaid hopes to expand its work to include oral health education and toothbrushing programmes.

Volunteers will stay in local hotels and will fly to the islands from Gatwick or Heathrow via Athens. Everyone taking part is asked to fundraise between $£ 700$ - $£ 750$ to pay for flights, accommodation and transport and a contribution for equipment and medicines.

For more information and to apply online visit www.dentaid.org or call 01794324249.

\title{
Calls for collaboration
}

\section{A diagnostic test for the application of endodontology \\ Shahnawaz writes:}

I am a qualified dentist from India and did my Masters from Queen Mary, University of London. Previously, I worked as an honorary lecturer at Queen Mary, Institute of Dentistry.

I am currently working on fluoride and osteoporosis and imaging. I am also working on community based research and product development.

My proposal is that I would like to develop a diagnostic test for the application of endodontology. I need collaborators who can work on the biotechnology aspect of the diagnostic test prototype development. I am happy to discuss this project further with potential collaborators. I am currently based in India.

Please email: khijmatgar.s@gmail.com.

Partners sought for licensing and marketing Davnik Silver Knight

A silver-based dental material has been developed in the UK which has the following benefits, amongst others, in treating decay:

1. Forms calcium fluoride which has a carious protective effect

2. Inhibits demineralisation of the tooth structure
3. Preserve dentine collagen from degradation

4. Silver has an intense antibacterial effect on cariogenic biofilms

5. Potent inhibiting effect on the activity of matrix metalloproteinases and cysteine cathepsin

6. Multiple use in children with decay

7. Can be used to treat sensitivity

8. The fluoride in the product promotes remineralisation while the silver acts as an antibacterial agent and plugs the dentinal tubules

9. The product is very cost effective

10. User friendly for operator and patient

11. Has ability to arrest decay in minutes.

Partners are sought for the licensing and marketing of the dental product which has been classified as a medicine. Sample kits are available to serious interested parties.

Dr D. Athimoolam says: 'We believe that this is the first product produced in the UK to effectively and efficiently treat dental decay'

Dr Athimoolam can be contacted either by email at: varabuds@yahoo.co.uk or mobile at: +447920153275 or by writing to: 39 Pippin Avenue, Trevethan Meadows, Liskeard, Cornwall, PL14 3FU.

\section{The $B D J$ is the most-read UK dental publication}

\section{The British Dental Journal has once again} been ranked by dentists as their number one preferred journal and the most-read UK dental publication, according to the newly-released BDIA Dental Media Readership Survey 2016.

The $B D J$ has led the polls since the survey began in 2005 and this latest achievement marks 12 years of consistent recognition:

- $93 \%$ of survey respondents were aware of the $B D J$, with $70 \%$ being aware of its sister publication, BDJ In Practice. Awareness of the $B D J$ was consistent among every age group

- The $B D J$ was the first choice preferred journal for $41 \%$ of respondents, followed by Dental Update (29\%) and Dentistry (7\%). The most popular reasons for choosing a publication were: clinical/ scientific articles, general dental news and educational opportunities

- $84 \%$ had recently read or looked at the $B D J, 12 \%$ ahead of other publications

- $21 \%$ of respondents had recently read or looked at the $B D J$ online, more than any other dental publication

- $B D J$ and BDJ In Practice were the most regularly read dental publications, by $44 \%$ and $32 \%$ of respondents respectively.

The $B D$ 's website was also praised by survey respondents for its variety of information, news, informative content and regular updates, and for its CPD and e-learning options.

\section{Denplan announces rebrand}

Denplan has announced that it is rebranding as Simplyhealth Professionals. Denplan first joined forces with Simplyhealth in 2011 and the two companies have been working together successfully ever since. Together the two companies have over 140 years of experience in the healthcare arena.

The company wants to focus on making Simplyhealth the most recognised public and professional brand in everyday health. Simplyhealth Professionals will continue to provide the full range of Denplan dental payment plans under the Denplan product name. The well-known Denplan apple logo will no longer be in use. 